\title{
Management of complications of ketamine abuse: 10 years' experience in Hong Kong
}

\author{
YL Hong, CH Yee, YH Tam, Joseph HM Wong, PT Lai, CF Ng *
}

\section{A B S T R A C T}

Ketamine is an $\mathrm{N}$-methyl-D-aspartate receptor antagonist, a dissociative anaesthetic agent and a treatment option for major depression, treatmentresistant depression, and bipolar disorder. Its strong psychostimulant properties and easy absorption make it a favourable candidate for substance abuse. Ketamine entered Hong Kong as a club drug in 2000 and the first local report of ketamine-associated urinary cystitis was published in 2007. Ketamine-associated lower-urinary tract symptoms include frequency, urgency, nocturia, dysuria, urge incontinence, and occasionally painful haematuria. The exact prevalence of ketamineassociated urinary cystitis is difficult to assess because the abuse itself and many of the associated symptoms often go unnoticed until a very late stage. Additionally, upper-urinary tract pathology, such as hydronephrosis, and other complications involving neuropsychiatric, hepatobiliary, and gastrointestinal systems have also been reported. Gradual improvement can be expected after abstinence from

This article was published on $6 \mathrm{Apr}$ 2018 at www.hkmj.org ketamine use. Sustained abstinence is the key to recovery, as relapse usually leads to recurrence of symptoms. Both medical and surgical management can be used. The Youth Urological Treatment Centre at the Prince of Wales Hospital, Hong Kong, has developed a four-tier treatment protocol with initial non-invasive investigation and management for these patients. Multidisciplinary care is essential given the complex and diverse psychological factors and sociological background that underlie ketamine abuse and abstinence status.

\section{Hong Kong Med J 2018;24:175-81}

DOI: 10.12809/hkmj177086

\section{${ }^{1}$ YL Hong, MSC}

${ }^{2} \mathrm{CH}$ Yee, FHKAM (Surgery)

YH Tam, FHKAM (Surgery)

2 JHM Wong, FHKAM (Surgery)

${ }^{2}$ PT Lai, BN

${ }^{2} \mathrm{CF} \mathrm{Ng}{ }^{*}$, FHKAM (Surgery)

${ }^{1}$ Division of Paediatric Surgery and Paediatric Urology, Department of Surgery,

2 SH Ho Urology Centre, Department of Surgery,

The Chinese University of Hong Kong, Shatin, Hong Kong

* Corresponding author: ngcf@surgery.cuhk.edu.hk

\section{Introduction}

Ketamine is an N-methyl-D-aspartate (NMDA) receptor antagonist, a dissociative anaesthetic agent that was first synthesised in the United States in 1962. It has been widely used in both human and veterinary medicine since 1971. It has also been used as a treatment for major depression, treatmentresistant depression, and bipolar disorder. ${ }^{1}$ However, its strong psychostimulant properties and easy absorption make it a favourable candidate for substance abuse. Ketamine abuse has become increasingly common over the past two decades. It entered Hong Kong as a club drug in 2000 and was initially used as a 'top-up' drug to ecstasy (3,4-methylenedioxymethamphetamine) by those aiming to elevate and redirect the 'high.' ${ }^{2}$ It was viewed as a poor man's version of cocaine, as it is available in powder form and can be consumed by snorting. By 2002, ketamine had become the drug of choice instead of a 'top-up' drug. Users selfadministered ketamine to have a 'time-out' or 'sitdown-to-float' experience., ${ }^{2,3}$ Within a short period, the number of reported ketamine abusers in Hong Kong increased from 1605 in 2000 to its peak of
5280 in 2009. Ketamine remained the most popular psychotropic substance abused from 2005 to 2014 (Fig 1). ${ }^{4}$

The abuse of ketamine and its popularity nonetheless created a new medical entity. The first report of ketamine-associated urinary cystitis in Hong Kong was published in 2007. ${ }^{5}$ In the same year, Shahani et al reported a similar condition overseas. ${ }^{6}$ In the past decade, owing to the joint efforts of urologists, general surgeons, physicians, psychiatrists, pathologists, and basic scientists, we have gained a better understanding of other ketamine-associated conditions. This understanding spans from pathology to clinical management, from urological complications to upper-gastrointestinal (GI) complications, and from a mouse model to humans. We have also explored holistic ways to manage this condition in the long term, such as helping young adults to have a fresh start while living with potentially irreversible complications. This article reviews the evolution of local clinical awareness and management of these complications, with a particular focus on the work and contributions of local researchers. 


\section{氯胺酮濫用的併發症治療：香港十年經驗}

匡若琳、余知行、譚煜謙、黃翰明、黎珮德、吳志輝

氯胺酮是一種 $\mathrm{N}$-甲基 $-\mathrm{D}$-天冬氨酸受體拮抗劑、一種解離麻醉劑,

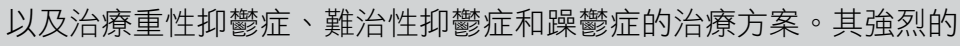
精神興奮劑特性和易吸收性使其成為常見的藥物濫用選項。氯胺酮於 2000 年作為俱樂部毒品藥物進入香港, 2007 年發佈首宗與氯胺酮相關 的尿路膀胱炎病例。氯胺酮相關的下尿路症狀包括頻率、尿急、夜尿 症、排尿困難、急迫性尿失禁以及偶爾疼痛性血尿。氯胺酮相關膀胱 炎的確切發病率難以評估, 因為與濫藥及許多相關症狀常於炎症後期 才被發現。現時的醫學文獻還包括上尿路病理如腎積水, 以及涉及神 經精神病學、肝膽和胃腸系統的其他併發症報告。戒用氯胺酮有望逐 漸改善上述病症的趨勢, 持續戒毒也是康復的關鍵, 因為復用常引致 症狀復發。藥物和手術均是可行的治療方案。香港威爾斯親王醫院青 少年泌尿治療中心已制定四級治療方案, 對這些患者進行初步無創性 評估和治療。考慮到氯胺酮濫用和禁慾狀態其複雜多樣的心理因素和 社會背景, 多學科護理是必不可少的。

\section{Urological complications}

Chu et $\mathrm{al}^{5}$ reported the first local case series of ketamine-associated bladder dysfunction in 2007. Ketamine-associated lower-urinary tract symptoms (LUTS) include frequency, urgency, nocturia, dysuria, urge incontinence, and occasionally painful haematuria. The exact prevalence of ketamine-associated urinary cystitis is difficult to assess because ketamine abuse and many of the associated symptoms often go unnoticed until a very late stage. A survey among 12000 local secondary school students revealed that $18.5 \%$ of non-psychotropic substance users had LUTS, whereas $47.8 \%$ and $60.7 \%$ of psychotropic substance users and ketamine users had LUTS, respectively. ${ }^{7}$ Unpublished data from the same study showed that compared with non-psychotropic substance users, sole ketamine users were five times as likely to have LUTS, whereas concomitant users of ketamine and

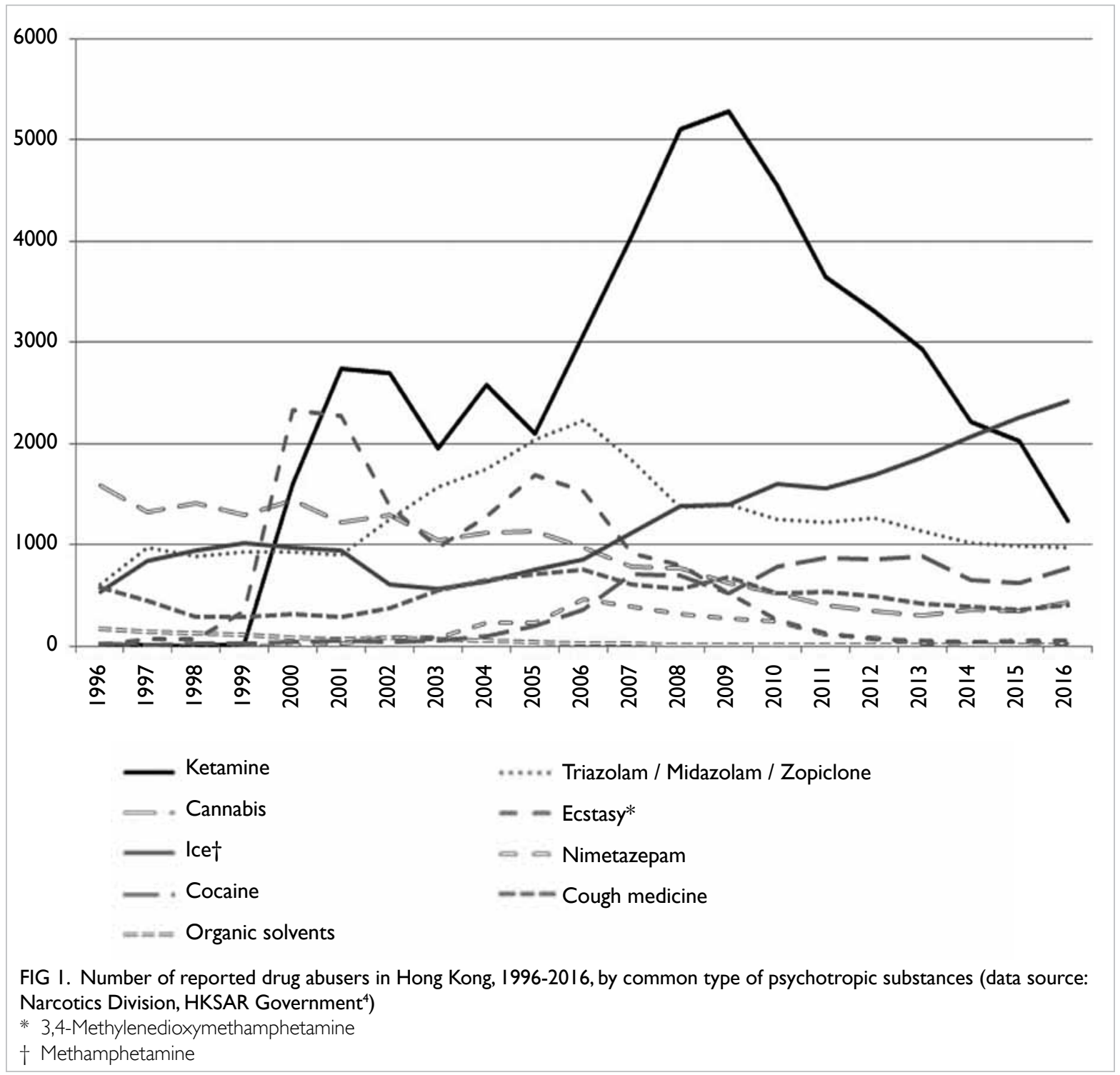


methamphetamine were eight times as likely to have LUTS.

In 2015, Yee et $\mathrm{al}^{8}$ reported the largest available cohort of both active and past ketamine users who had ketamine-associated uropathy. Among 463 patients, ketamine users had a significantly higher pelvic pain and urgency/frequency (PUF) score than ex-ketamine users. The PUF score is initially used to assess interstitial cystitis, and a higher PUF score correlates with worse symptoms. Among active ketamine users, a higher PUF score was found to correlate with a poorer quality of life and a smaller functional bladder capacity. ${ }^{8}$ Achieving abstinence from ketamine use and consuming smaller amounts of ketamine were factors that predicted improvement in PUF score.

As well as bladder involvement, upper-urinary tract pathology presenting as hydronephrosis and flank pain has also been reported (Fig 2). A study by Yee et $\mathrm{al}^{9}$ of 572 patients with ketamine-related LUTS found that up to $16.8 \%(n=96)$ of patients had hydronephrosis according to ultrasonography. Hydronephrosis was frequently accompanied by ureteral lesions, ureteral wall thickening, or vesicoureteral (vesicoureteric) reflux. Similarly, Chu et $\mathrm{a}^{10}$ reported that $51 \%(30 / 59)$ of their patients had hydronephrosis according to ultrasonography.

\section{Pathophysiology}

Although the exact mechanism of ketamineassociated cystitis remains to be explored, there is evidence that ketamine metabolites in the urine induce chemical irritation of the urothelium, thereby causing an inflammatory response. ${ }^{11}$ Severe irritation may lead to denudation of the urothelium and consequent transmural inflammation, loss of muscle thickness, fibrosis of the detrusor muscle, and ultimately poor urinary bladder compliance. Vesicoureteral reflux or urinary stasis in the ureter may occur, causing chronic ureteral inflammation and ureteral stricture. There is also evidence that both systemic and local inflammatory markers are elevated in ketamine users. ${ }^{10,12}$ In addition, the NMDA antagonist properties of ketamine may exert their effect via a central pathway. ${ }^{13}$

\section{Neuropsychiatric complications}

As ketamine is a psychostimulant, it is not surprising that it is associated with long-term neurocognitive problems. Chan et $\mathrm{al}^{14}$ found that when ketamine users were compared with healthy controls, they had impaired verbal fluency, cognitive processing speed, and verbal learning. Heavy ketamine use correlated with deficits in verbal memory and visual recognition memory. Liang et al $^{15}$ also identified predominant verbal and visual memory impairment in ketamine poly-drug users. Unfortunately, these

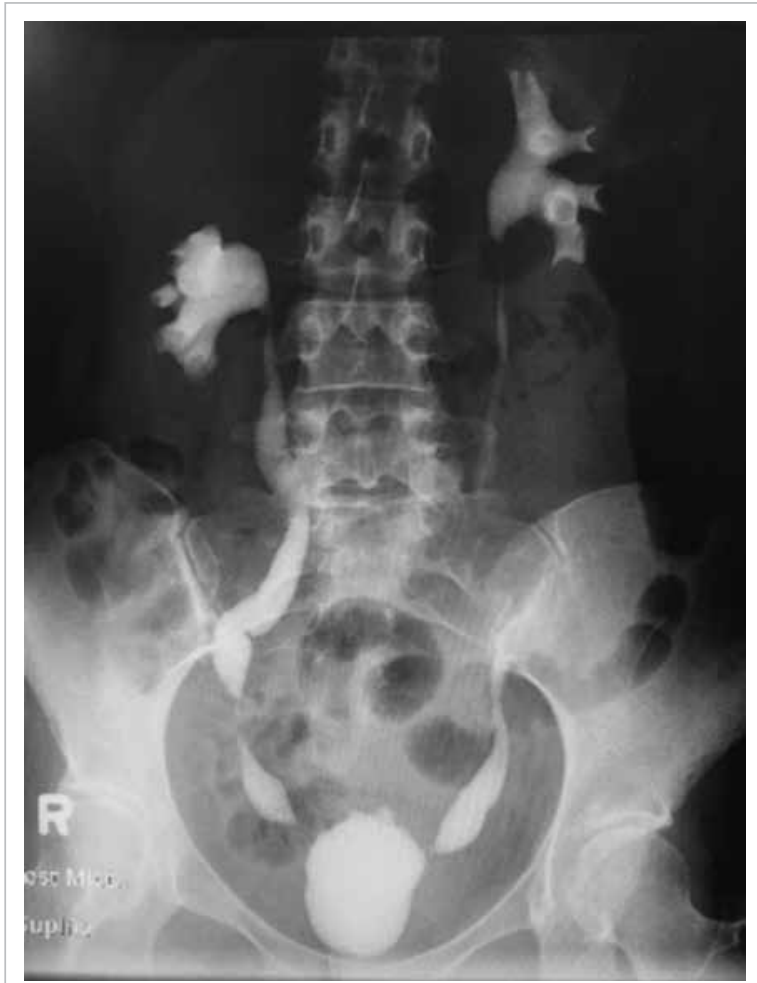

FIG 2. Intravenous urogram of a 28-year-old woman presenting to the Prince of Wales Hospital, showing bilateral hydronephrosis and small bladder

deficits persisted in ex-users. A much higher incidence of psychiatric co-morbidities, including psychosis, depression, and anxiety, was observed among ketamine users. ${ }^{16}$

\section{Pathophysiology}

Structural brain damage associated with ketamine abuse was supported by magnetic resonance imaging (MRI) by Wang et al. ${ }^{17}$ They were the first group to report patches of degeneration in the superficial white matter as early as 1 year after ketamine addiction onset. Cortical atrophy was also found in the frontal, parietal, or occipital cortices of addicts. ${ }^{17}$ Another MRI study also provided evidence of brain damage in chronic ketamine users. Reduced grey- and white-matter volumes were noted in the bilateral orbitofrontal cortex, right medial prefrontal cortex, and bilateral hippocampi. There was also significantly decreased connectivity inside the brain in chronic ketamine abusers. ${ }^{18}$

A series of studies on the neurotoxicity of ketamine suggested that ketamine could cause apoptosis of neuronal cells in both in-vitro and in-vivo models. Ketamine also potentially causes phosphorylation of tau protein, a marker of Alzheimer's degeneration in the brain. ${ }^{19-22}$ 


\section{Hepatobiliary complications}

In 2009, Wong et $\mathrm{al}^{23}$ reported ketamine-associated hepatobiliary complications for the first time. Three ketamine abusers presented with recurrent epigastric pain and dilated bile ducts mimicking choledochal cysts. Subsequently, more similar cases were identified. Fusiform dilatation of the common bile duct was also observed. ${ }^{24-26}$ Liver biopsy confirmed development of active liver and/or bile duct injury. A study of 297 chronic ketamine abusers with urinary tract dysfunction showed that the prevalence of liver injury was $9.8 \%{ }^{27}$ These studies and reports show the possibility and severity of damage by ketamine to the hepatobiliary and pancreatic system.

\section{Pathophysiology}

The exact mechanism of ketamine-associated bile injury is still unknown. The associated rise in Creactive protein suggests a possible inflammatory process in the liver parenchyma, including or excluding the bile duct. ${ }^{27}$ Others have postulated that either central or direct action of ketamine on the biliary smooth muscle in turn leads to the cholestasis and biliary dilatation observed in ketamine abusers. ${ }^{28}$

\section{Gastrointestinal complications}

In addition to urological complaints, GI problems are also frequently the symptoms for which ketamine abusers seek medical help. A review of 233 ketaminerelated visits to accident and emergency departments found that $49(21.0 \%)$ patients had abdominal pain, $23(9.9 \%)$ had nausea or vomiting, and 41 (17.6\%) had abdominal tenderness. ${ }^{29}$ Gastrointestinal complaints often co-exist with and precede the presentation of urological symptoms. Liu et $\mathrm{al}^{30}$ found that about a quarter $(168 ; 27.5 \%)$ of 611 ketamine users who sought treatment for ketamine uropathy reported the presence of upper-GI symptoms, whereas only $42(5.2 \%)$ of 804 non-ketamine users attending a general urology clinic reported similar symptoms $(P<0.001)$. The majority of the symptoms reported were epigastric pain and recurrent vomiting. Nearly three-quarters of patients required hospitalisation for acute or chronic upper-GI symptoms. With the exception of acid reflux and perforated peptic ulcer, the prevalence of all the above-mentioned symptoms and hospitalisation rates were statistically significantly higher in ketamine users than in nonketamine users. All 168 patients using ketamine had undergone oesophagogastroduodenoscopy during which biopsies were taken. Pathological findings ranged from gastritis to gastroduodenal erosions, peptic ulceration, and intestinal metaplasia. ${ }^{30}$

Liu et $\mathrm{al}^{30}$ also found that more than $80 \%$ of patients developed upper-GI symptoms before urological symptoms. Patients developed upper-GI symptoms after a mean (standard deviation) of 5.1
(3.1) years of ketamine use and developed uropathy symptoms after another 4.4 (3.0) years of ketamine use. ${ }^{30}$ Epigastric symptoms are not common in young people, but common in ketamine abusers. This difference may provide an opportunity to identify hidden ketamine abuse when assessing young patients with epigastric symptoms. The identification of ketamine use is important, as cessation of use can greatly improve GI symptoms. ${ }^{31}$ Further referral for help and counselling may improve psychological and physical health and promote long-term ketamine abstinence.

\section{Pathophysiology}

The exact pathophysiological mechanism by which ketamine produces upper-GI toxicity remains unknown but there are several postulations. First, ketamine, as an NMDA antagonist, might act on local smooth muscle or the central nervous system, thereby affecting gastric motility and leading to cramping pain. Second, microvascular damage by ketamine and its metabolites, which was believed to be a possible cause of ketamine uropathy, might also cause similar microvascular damage in the stomach and duodenum, leading to ischaemic pain and inflammation. Likewise, circulating ketamine might also trigger some unknown autoimmune responses, and thus induce interstitial inflammation in the urinary and GI tracts. Finally, as many ketamine abusers like to swallow the nasal drips occurring from ketamine inhalation, the swallowed ketamine might also induce direct cytotoxic injury to the vulnerable GI tract. ${ }^{30}$

\section{Management}

As in the management of other substance abuse, abstinence is the key to success in overall management of ketamine use. Whereas other treatment modalities may relieve symptoms and hasten the recovery process, many ketamine abusers have complicated underlying psychosocial problems and psychiatric co-morbidities. Long-term and consistent support and encouragement from doctors, nurses, social workers, family, and friends are vital for success.

\section{Abstinence from ketamine use}

Recurrence of symptoms after resuming ketamine use highlights the importance of ketamine abstinence. Studies have shown that abstinence leads to symptomatic improvement. Compared with active ketamine abusers, those who had abstained for 1 year had significantly lower PUF scores and a larger voided volume. There was a trend towards higher voided volumes and lower PUF scores as duration of ketamine cessation increased, although neither variable was statistically significant. ${ }^{32}$ Another follow-up study of 101 participants who 
had abstained from ketamine and 218 active ketamine users showed that the abstinence group had a statistically significantly lower PUF score, and a higher functional bladder capacity. ${ }^{8}$ Moreover, abstinence was the only protective factor associated with fewer symptoms, larger voided volume, and bladder capacity. ${ }^{33}$

Nonetheless, abstinence does not lead to immediate and full recovery of symptoms. Gradual improvement can be expected but sustained abstinence is the key to recovery. Patience and continuous support are of paramount importance. A study showed that on admission to a drug rehabilitation centre, $90 \%$ of 40 female ex-ketamine users still hadactiveurinary symptoms, with increased 24-hour urinary frequency, lower maximum voided volume, smaller median functional bladder capacity, and higher mean Urogenital Distress Inventory Short Form (UDI-6) and Incontinence Impact
Questionnaire Short Form (IIQ-7) scores, when compared with age-matched controls who attended a general gynaecology clinic. After having stopped using ketamine for 3 months or more, mean 24-hour urinary frequency and mean UDI-6 and IIQ-7 scores decreased, and maximum voided volume increased. These scores further improved after another 3 months, although this group continued to perform more poorly in all aspects compared with controls. ${ }^{34}$

\section{Medical and surgical management}

As ketamine-associated uropathy is an evolving 'disease entity', the exact pathophysiology remains to be elucidated. Some of the clinical features share similarities with interstitial cystitis. Protocols are being developed to cater to the needs of patients in Hong Kong. A one-stop service model has been adopted by the Youth Urological Treatment Centre at the Prince of Wales Hospital since 2011 (Fig 3).

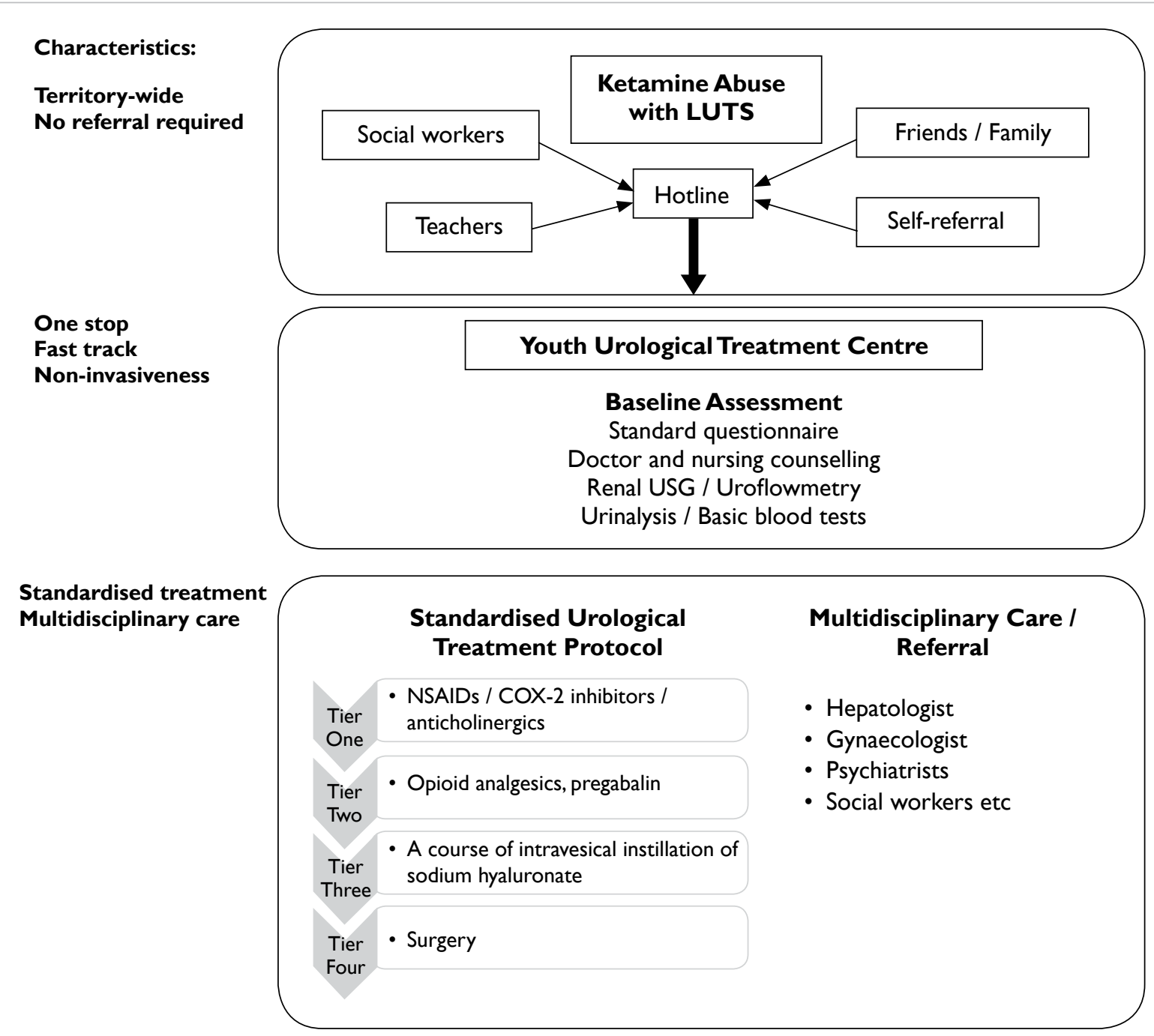

FIG 3. One-stop screening clinic model of the Youth Urological Treatment Centre, Prince of Wales Hospital, Hong Kong Abbreviations: $\mathrm{COX}=$ cyclo-oxygenase; $\mathrm{LUTS}=$ lower-urinary tract symptoms; NSAID = non-steroidal anti-inflammatory drug; USG = ultrasonography 
The standard treatment protocol involves four tiers of treatment, starting with an initial non-invasive investigative approach, including questionnaire assessment of symptoms and calculation of (1) functional bladder capacity by measuring voided volume using uroflowmetry and (2) residual urine using ultrasound bladder scanning. This noninvasive investigative approach helps gain patients' trust and improve adherence to later follow-up.

First-tier treatment includes oral non-steroidal anti-inflammatory drugs (NSAIDs) (eg, diclofenac) and anticholinergics (eg, solifenacin) or COX-II inhibitors (eg, etoricoxib) if patients cannot tolerate NSAIDS. Simple analgesics such as paracetamol and phenazopyridine are used for pain control. The Youth Urological Treatment Centre has reported the largest series of patients with ketamine-associated uropathy and their corresponding outcomes. Of 290 patients with ketamine cystitis who received first-line treatment, 202 (69.7\%) reported symptom improvement and a reduction in PUF scores. Functional bladder capacity was also shown to have improved. ${ }^{8}$

The opioid group of analgesics and pregabalin are used in the next tier of pain-control treatment when first-tier treatment is insufficient for symptom relief. Sixty-two patients received second-line treatment and $42(67.7 \%)$ responded to treatment. ${ }^{8}$

Third-tier treatment consists of a course of intravesical instillation of sodium hyaluronate (6-weekly instillations followed by 2 -monthly instillations) attempting to repair the glycosaminoglycan layer. The drug is given to patients whose symptoms remain uncontrolled after second-tier treatment. Seventeen patients in the cohort received the third-tier treatment and eight completed the course. Significant improvement in voided volume was noted and five were able to reduce their oral medication usage after treatment. No significant adverse effects were reported. ${ }^{8}$

Unfortunately, for a proportion of patients with extremely refractory symptoms, surgery becomes the fourth-tier treatment of choice. In the Youth Urological Treatment Centre series, one patient in the cohort required hydrodistension and another underwent robotic-assisted laparoscopic augmentation cystoplasty. The patient with hydrodistension experienced a recurrence of symptoms post-treatment. ${ }^{8} \mathrm{Ng}$ et $\mathrm{al}^{35}$ reported on four patients who underwent augmentation cystoplasty. Although they showed initial improvement, all patients relapsed and resumed ketamine use postoperatively. Three of the patients showed a further deterioration in renal function, secondary to new-onset ureteral strictures and/or sepsis. Therefore, patient selection, education, close follow-up, and support are vital to the success of augmentation cystoplasty. ${ }^{35}$

\section{Multidisciplinary care}

Given the complex and diverse psychological factors and sociological background contributing to an individual's decision to abuse ketamine or achieve abstinence, joint multidisciplinary efforts are required to help affected young adults. Doctors, social workers, teachers, psychiatrists, psychologists, nurses, and patients' families all need to support them on their long road to recovery, to help them rehabilitate physically and achieve sustained abstinence from ketamine. ${ }^{33,36,37}$

\section{Conclusion}

Since the initial discovery of ketamine-associated uropathy, the impact of this disease entity has become more prominent in Asian countries. Thanks to the joint efforts of urologists, gynaecologists, surgeons, psychiatrists, pathologists, and social workers, as well as the support of local government, the extent of medical complications has been revealed to also involve the brain, liver, and GI system. Many ketamine abusers are 'hidden' and can use ketamine stealthily at home for years without their family noticing. Clinicians must take the opportunity to identify hidden abusers when they consult for non-specific symptoms such as epigastric pain and LUTS. Doing so will not only enable early diagnosis of ketamine-associated uropathy, but it will also help provide appropriate medical treatment in a timely manner. In addition to medical therapy, referral for appropriate psychosocial support is essential to sustain abstinence and manage underlying psychosocial problems.

\section{Acknowledgement}

The Youth Urological Treatment Centre was developed by joint efforts of The Chinese University of Hong Kong and the Hong Kong Hospital Authority, with generous support from the Beat Drugs Fund of the Narcotics Division, Security Bureau, Government of the Hong Kong Special Administrative Region.

\section{Declaration}

The authors have no conflicts of interest to disclose.

\section{References}

1. Hasselmann HW. Ketamine as antidepressant? Current state and future perspectives. Curr Neuropharmacol 2014;12:57-70.

2. Joe Laidler KA. The rise of club drugs in a heroin society: the case of Hong Kong. Subst Use Misuse 2005;40:1257-78.

3. Joe-Laidler K, Hunt G. Sit down to float: the cultural meaning of ketamine use in Hong Kong. Addict Res Theory 2008;16:259-71.

4. Narcotics Division, Security Bureau, HKSAR Government. 
Statistical tables customization. Available from: http:// cs-crda.nd.gov.hk/en/enquiry.php. Accessed 22 Sep 2017.

5. Chu PS, Kwok SC, Lam KM, et al. 'Street ketamine'associated bladder dysfunction: a report of ten cases. Hong Kong Med J 2007;13:311-3.

6. Shahani R, Streutker C, Dickson B, et al. Ketamineassociated ulcerative cystitis: a new clinical entity. Urology 2007;69:810-2

7. Tam YH, Ng CF, Wong YS, et al. Population-based survey of the prevalence of lower urinary tract symptoms in adolescents with and without psychotropic substance abuse. Hong Kong Med J 2016;22:454-63.

8. Yee CH, Lai PT, Lee WM, et al. Clinical outcome of a prospective case series of patients with ketamine cystitis who underwent standardized treatment protocol. Urology 2015;86:236-43.

9. Yee $\mathrm{CH}$, Teoh YC, Lai PT, et al. The risk of upper urinary tract involvement in patients with ketamine-associated uropathy. Int Neurourol J 2017;21:128-32.

10. Chu PS, Ma WK, Wong SC, et al. The destruction of the lower urinary tract by ketamine abuse: a new syndrome? BJU Int 2008;102:1616-22.

11. Chu PS, Ng CF, Ma WK. Ketamine uropathy: Hong Kong experience. In: Yew DT, editor. Ketamine: Use and Abuse. CRC Press; 2015: 207-26.

12. Division of Urology, Department of Surgery, Princess Margaret Hospital and Tuen Mun Hospital. Research on Urological Sequelae of Ketamine Abuse. Available from: http://www.nd.gov.hk/pdf/20110307_beat_drug_fund_ report.pdf. Accessed 22 Sep 2017.

13. Jankovic SM, Jankovic SV, Stojadinovic D, et al. Effect of exogenous glutamate and $\mathrm{N}$-methyl-D-aspartic acid on spontaneous activity of isolated human ureter. Int J Urol 2007;14:833-7.

14. Chan KW, Lee TM, Siu AM, et al. Effects of chronic ketamine use on frontal and medial temporal cognition. Addict Behav 2013;38:2128-32.

15. Liang HJ, Lau CG, Tang A, et al. Cognitive impairments in poly-drug ketamine users. Addict Behav 2013;38:2661-6.

16. Tang WK, Morgan CJ, Lau GC, et al. Psychiatric morbidity in ketamine users attending counselling and youth outreach services. Subst Abus 2015;36:67-74.

17. Wang $\mathrm{C}$, Zheng $\mathrm{D}, \mathrm{Xu} \mathrm{J}$, et al. Brain damages in ketamine addicts as revealed by magnetic resonance imaging. Front Neuroanat 2013;7:23.

18. Narcotics Division, Security Bureau, HKSAR Government. Evidence of Brain Damage in Chronic Ketamine Users-a Brain Imaging Study. Available from: http://www.nd.gov. hk/pdf/Evidence-of-Brain-Damage-in-Chronic-KetamineUsers_Final-report.pdf. Accessed 22 Sep 2017.

19. Yeung LY, Wai MS, Fan M, et al. Hyperphosphorylated tau in the brains of mice and monkeys with long-term administration of ketamine. Toxicol Lett 2010;193:18993.

20. Narcotics Division, Security Bureau, HKSAR Government. Long-term Ketamine Abuse and Apoptosis in Cynomolgus Monkeys and Mice. Available from: http://www.nd.gov. hk/pdf/long term_ketamine abuse apoptosis_in cynomologus_monkeys_and_mice/final_report_with_all_ attachments.pdf. Accessed 22 Sep 2017.

21. Tan S, Rudd JA, Yew DT. Gene expression changes in GABA(A) receptors and cognition following chronic ketamine administration in mice. PLoS ONE 2011;6:e21328.

22. Mak YT, Lam WP, Lü L, et al. The toxic effect of ketamine on SH-SY5Y neuroblastoma cell line and human neuron. Microsc Res Tech 2010;73:195-201.

23. Wong SW, Lee KF, Wong J, et al. Dilated common bile ducts mimicking choledochal cysts in ketamine abusers. Hong Kong Med J 2009;15:53-6.

24. Ng SH, Lee HK, Chan YC, et al. Dilated common bile ducts in ketamine abusers. Hong Kong Med J 2009;15:157.

25. Cheung TT, Poon RT, Chan AC, et al. Education and imaging. Hepatobiliary and pancreatic: cholangiopathy in ketamine user-an emerging new condition. J Gastroenterol Hepatol 2014;29:1663.

26. Lui KL, Lee WK, Li MK. Ketamine-induced cholangiopathy. Hong Kong Med J 2014;20:78.e1-2.

27. Wong GL, Tam YH, Ng CF, et al. Liver injury is common among chronic abusers of ketamine. Clin Gastroenterol Hepatol 2014;12:1759-62.e1.

28. Lo RS, Krishnamoorthy R, Freeman JG, et al. Cholestasis and biliary dilatation associated with chronic ketamine abuse: a case series. Singapore Med J 2011;52:e52-5.

29. Ng SH, Tse ML, Ng HW, et al. Emergency department presentation of ketamine abusers in Hong Kong: a review of 233 cases. Hong Kong Med J 2010;16:6-11.

30. Liu SY, Ng SK, Tam YH, et al. Clinical pattern and prevalence of upper gastrointestinal toxicity in patients abusing ketamine. J Dig Dis 2017;18:504-10.

31. Poon TL, Wong KF, Chan MY, et al. Upper gastrointestinal problems in inhalational ketamine abusers. J Dig Dis 2010;11:106-10.

32. Mak SK, Chan MT, Bower WF, et al. Lower urinary tract changes in young adults using ketamine. J Urol 2011;186:610-4.

33. Tam YH, Ng CF, Pang KK, et al. One-stop clinic for ketamine-associated uropathy: report on service delivery model, patients' characteristics and non-invasive investigations at baseline by a cross-sectional study in a prospective cohort of 318 teenagers and young adults. BJU Int 2014;114:754-60.

34. Cheung RY, Chan SS, Lee JH, et al. Urinary symptoms and impaired quality of life in female ketamine users: persistence after cessation of use. Hong Kong Med J 2011;17:267-73.

35. Ng CF, Chiu PK, Li ML, et al. Clinical outcomes of augmentation cystoplasty in patients suffering from ketamine-related bladder contractures. Int Urol Nephrol 2013;45:1245-51.

36. Ng CF. Editorial comment to possible pathophysiology of ketamine-related cystitis and associated treatment strategies. Int J Urol 2015;22:826.

37. Chu PS, Dasgupta P. Lessons learned from Asian Urology. BJU Int 2014;114:633. 